\title{
COMPLICACIÓN INUSUAL POST-CIRCUNCISIÓN
}

\section{J. HERRERA PUERTO*, J. HERRERA FLORES*, J. FERNÁNDEZ IGLESIAS**, M. MARRENO CALVO**, N. BURGUILLO JIMÉNEZ**}

*Servicio de Urología. **Servicio de Pediatría. Hospital Ntra. Sra. de Sonsoles. Ávila.

Actas Urol Esp. 27 (7): 559-561, 2003

\section{RESUMEN}

COMPLICACIÓN INUSUAL POST-CIRCUNCISIÓN

Cualquier cirugía por intrascendente que parezca puede ocasionar complicaciones pero una infección del pene después de una circuncisión es un hecho poco habitual.

Se trata de una enfermo prepúber que en el post-operatorio inmediato tras una circuncisión presentó un absceso de pene.

Se analizan los aspectos epidemiológicos, etiopatogénicos y terapéuticos de la infección peneana siguiente a una circuncisión.

PALABRAS CLAVE: Pene. Circuncisión. Infección.

\section{ABSTRACT \\ UNUSUAL COMPLICATION POST CIRCUMCISION}

Any surgery for ordinary that it's seen can be to cause the complications but at infection of the penis after circumcision is a rare occurence.

We report a prepuber patient who on the immediately surgery after circumcision was present a penis abscess.

The epidemiological, etiopathogenic aspects and therapeutic are analyzed of the penis infection after a circumcision.

KEY WORDS: Penis. Circumcision. Infection.

$\mathrm{L}^{2}$ a circuncisión es un procedimiento quirúrgico no complejo pero tampoco inocuo y, en clínica diaria, se recomienda sea practicado por profesionales con suficiente experiencia en cirugía para conseguir los efectos deseados ${ }^{1}$.

La infección del pene, en el postoperatorio inmediato de una circuncisión, es una complicación rara pero puede convertirse en catastrófica $^{2}$.

Se aporta un raro caso a la literatura nacional, y se hace una puesta a punto bibliográfica de esta infrecuente manifestación tras una cirugía correctora balano-prepucial.

\section{CASO CLÍNICO}

Niño de 13 años, sin antecedentes de interés, remitido a urgencias desde Atención Primaria, por dolor y edema en prepucio y raíz de escroto junto a emisión de pus achocolatado a través de glande tras retirar un vendaje peneano, al 5ํํa, de una circuncisión practicada por fimosis prepucial; recibió tratamiento con amoxicilina y clavulámico sin experimentar mejoría.

A la exploración, destacaba buen desarrollo somático. Aprensivo. Febrícula. Normotenso. Tonos cardíacos rítmicos. Bien perfundido. Ausencia de adenovisceromegalias. Puño-percusión renal, negativa. Disuria inicial. Genitales externos no ambiguos, presentando estado flegmonoso en la totalidad del pene y raíz de escroto con placas de piel violáceas en prepucio, exteriorizándose un exudado verde-cremoso, abundante, a la mínima expresión a través de la herida operatoria (Fig. 1); no orquiepididimitis. 


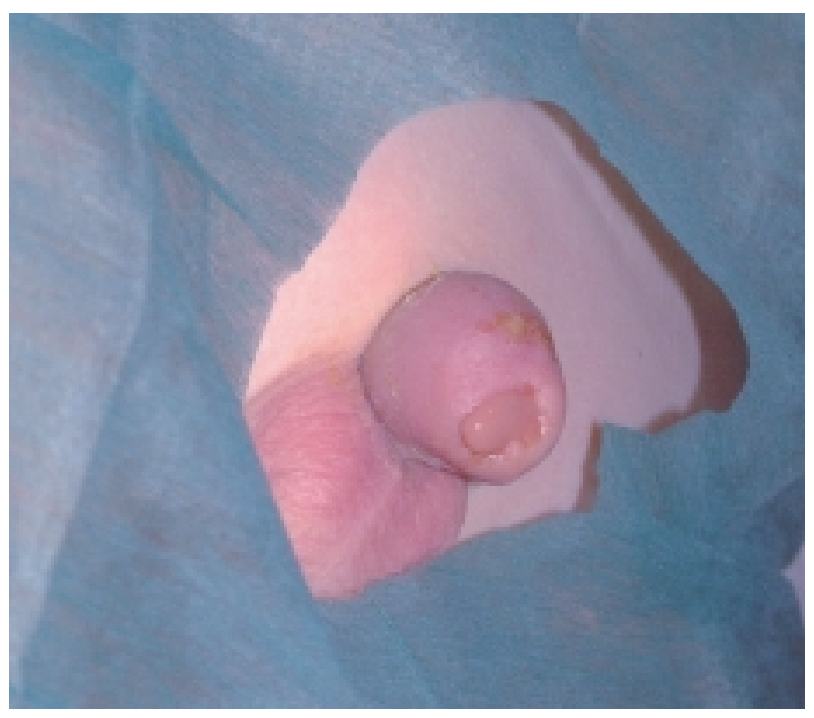

FIGURA 1. Emisión de pus achocolatado a través de la herida operatoria balanoprepucial.

Analítica: leucocitosis y neutrofilia; glucemia, urea y plaquetas, normales; $68 \%=$ actividad de protrombina y $418 \mathrm{mgr} / \mathrm{dl}=$ fibrinógeno; orina de ph ácido y leucohematuria; cultivo del exudado negativo, para bacterias y levaduras.

Rfx Tórax: sin hallazgos. ECG: en ritmo sinusal.

Con el diagnóstico de absceso de pene, previa cobertura antibiótica con metronidazol y cefalosporinas parenterales, a dosis pediátricas, se procedió a la evacuación quirúrgica del pus mediante lavados con agua oxigenada y povidona yodada diluida a través de la plastia dehiscente, Friederich amplio de las fascias de Buck y Colles, y colocación de varios drenajes de penrose en la base del pene.

Pasados 3 meses de seguimiento ambulatorio, ha precisado la realización de cirugía reconstructora balanoprepucial, por intensa esclerosis, con resultado funcional y cosmético satisfactorio.

\section{DISCUSIÓN}

La circuncisión es uno de los gestos quirúrgicos más habituales en urología infantil, llegándose a convertir en el procedimiento urológico más frecuentemente realizado en EE.UU, generalmente en chicos en edad pediátrica ${ }^{3}$.

Es conocida como una de las intervenciones quirúrgicas más antiguas de la historia, pues hay evidencias, en las momias del antiguo Egipto, sobre su práctica ${ }^{4}$. Si bien su origen no está del todo claro, inicialmente fue incorporada como un rito religioso en diversas etnias y religiones, pero con el transcurrir del tiempo se le adjudicó una acción profiláctica, por motivos de higiene ${ }^{5}$.

Aunque existe discrepancia a cerca de los criterios para recomendar una circuncisión, es aceptado que las indicaciones deben ser solamente por razones médicas y no por motivos de carácter social, cultural o religioso ${ }^{6}$.

El objetivo de la circuncisión es resecar suficiente mucosa balánica y epitelio prepucial que deje descubierto al glande, consiguiendo el mejor beneficio estético ${ }^{5}$.

Existen diferentes técnicas quirúrgicas para circuncidar pero todas tienen limitaciones y críticas, y los resultados dependen de la experiencia del cirujano y técnica empleada ${ }^{7}$.

La incidencia de complicaciones varía entre un $2-10 \%{ }^{8}$, tales como la fístula uretrocutánea, estenosis de meato, trastornos psicológicos y sexuales hasta una gran miscelánea pero son la hemorragia e infección los problemas intraoperatorios que causan mayor morbilidad ${ }^{6}$.

La infección ocurre en el $10 \%$ de pacientes ${ }^{9}$, manifestándose por cambios inflamatorios que ocasionalmente pueden llegar a la ulceración y supuración, o la gangrena por fascitis; raramente, derivan en complicaciones más severas, como la sépsis ${ }^{10}$.

La piel del pene y escroto así como del periné está colonizada por gérmenes saprofitos habituales y flora intestinal, tipo cocos y bacilos gram positivos, difteroides y clostridium; la puerta de entrada para la contaminación, por estos microorganismos, es la herida operatoria balanoprepu$\mathrm{cial}^{4}$, favorecida por un ambiente ausente de aire como es un vendaje mantenido varios días ${ }^{10}$, tal como sucedió en el caso comunicado.

La mayoría de infecciones peneanas tienen escasa trascendencia, curando con terapéutica local, pero ante un absceso de pene se impone el tratamiento con antibióticos de amplio espectro acompañado de desbridamiento y drenaje del pus $^{11}$, de igual manera que nosotros procedimos, para evitar consecuencias mayores.

Coincidimos con otros autores ${ }^{1,12}$, que una herida operatoria después de una circuncisión tiene que ser revisada en las 24 horas siguientes, vigilando su evolución, y aunque se trate de un proceder quirúrgico relativamente menor debería ser delegado a cirujanos con relativa solvencia. 


\section{REFERENCIAS}

1. OROZCO SJ, NERIVELA R.: Total denudation of the penis in circumcision. Description of a plastic technique for repair of the penis. Bol Med Hosp Infant Mex 1991; 48: 565-569.

2. DUMSMIR WD, GORDON EM.: The history of the circumcision. Br J Ur 1999; 31: 1-3.

3. BRISON PA, PATEL HI, FEIN NR.: Revision of circumcision in children: report of 56 cases. J Pediatr Surg 2002; 37: 1343-1346.

4. WILLIAMS N, KAPILA L.: Complications of circumcision. Br J Surg 1994; 81: 470-475.

5. LERMAN SE, LIAO JC.: Neonatal circumcision. Pediatr Clin North Am 2001; 48: 1539-1557.

6. HOLMAN R, STUESSI KA.: Adult circumcision. Am Fam Physician 1999; 59: 1514-1518.

7. CLAIR DL, CALDAMONE AA.: Pediatric office procedures. Urol Clin North Am 1988; 15: 715-723.

8. GRIFFITHS DS, ATWELL, FREEMAN NV.: A prospective study of the indications and morbility of circumcision in children. Eur Urol 1985; 11: 184-187.
9. AHDMED A, MBIBI N, DAWAM D, KALAYI G.: Complications of traditional male circumcision. Ann Trop Paediatr 1999; 19: 113-117.

10. BELKACEM R, AMRANI A, BENABDELLAH F, OUTARAHOUT O.: Reconstruction of the penis after necrosis due to circumcision. Ann Urol 1997; 31: 322-325.

11. CASALE AJ, BECK SD et al.: Concealed penis in chilhood: a spectrum of etiology and treatment. $J$ Urol 1999; 162: 1165-1168.

12. DAVEMPORT M.: ABC in general surgery in children problems with the penis and prepuce. $\mathrm{Br}$ Med $J$ 1996; 312: 7026-7028.

Dr. J. Herrera Puerto

C/ Bolivar, 24 - 3ㅇ C

37004 Salamanca

(Trabajo recibido el 4 marzo de 2002) 